OPEN ACCESS

Edited by:

Federica Scarpina,

University of Turin, Italy

Reviewed by:

Darlene A. Kertes,

University of Florida, USA

Giorgio Bertolotti,

Salvatore Maugeri Foundation, Italy

${ }^{*}$ Correspondence:

William Sulis

iratrofimov@gmail.com

Specialty section:

This article was submitted to

Psychology for Clinical Settings,

a section of the journal

Frontiers in Psychology

Received: 04 January 2016

Accepted: 23 February 2016

Published: 14 March 2016

Citation:

Trofimova I and Sulis W (2016) Benefits of Distinguishing between Physical and Social-Verbal Aspects of Behavior: An Example of Generalized Anxiety.

Front. Psychol. 7:338.

doi: 10.3389/fpsyg.2016.00338

\section{Benefits of Distinguishing between Physical and Social-Verbal Aspects of Behavior: An Example of Generalized Anxiety}

\section{Irina Trofimova and William Sulis*}

Collective Intelligence Laboratory, Department of Psychiatry and Behavioral Neurosciences, McMaster University, Hamilton, ON, Canada

Temperament traits and mental illness have been linked to varying degrees of imbalances in neurotransmitter systems of behavior regulation. If a temperament model has been carefully structured to reflect weak imbalances within systems of behavior regulation, then in the presence of mental illness, these profiles should exhibit distinct patterns consistent with symptoms of mental illness. In contrast to other temperament models used in studies of anxiety disorders, the Functional Ensemble of Temperament (FET) model differentiates not only between emotionality traits, but also between traits related to physical, social-verbal and mental aspects of behavior. This paper analyzed the predictions of the FET model, which maps 12 functional aspects of behavior to symptoms of generalized anxiety disorder (GAD) as described in the DSM/ICD. As an example, the paper describes a study of the coupling of sex, age and temperament traits with GAD using the FET framework. The intake records of 116 clients in treatment with confirmed diagnosis of GAD in a private psychological practice were compared using ANOVA against records of 146 healthy clients using their scores on the FET-based questionnaire, in age groups 17-24, 25-45, 46-65. Patients with GAD in all age groups reported significantly lower Social Endurance, Social Tempo, Probabilistic reasoning (but not in physical aspects of behavior) and higher Neuroticism than healthy individuals, however, no effects on the scales of Motor Endurance or Tempo were found. These findings show the benefits of differentiation between motor-physical and social-verbal aspects of behavior in psychological assessment of mental disorders.

Keywords: GAD, temperament, FET model, sociability, sex differences

\section{FUNCTIONAL PERSPECTIVE AND FUNCTIONAL ENSEMBLE OF TEMPERAMENT MODEL (FET) AS A FRAMEWORK FOR MAPPING INDIVIDUAL DIFFERENCES}

The classification of individual differences in psychology has developed from several different perspectives. The Five-Factors model, for example, was developed based on a factor analysis of lexical descriptors of personality characteristics, overlooking a strong sociability bias among these descriptors. Language developed historically to optimize people's socialization, consequently, language has more words describing aspects of socialization in comparison to those describing physical and mental aspects of behavior. Language also reflects a negativity bias of emotionality, with more words describing 
negative than positive emotions (see Trofimova, 2014; Trofimova and Sulis, submitted for details). Thus studies using the Five Factor model consistently show large Extraversion and Neuroticism factors - reflecting the sociability and negative emotionality biases in language rather than the deeper structure of individual differences.

One alternative approach to human diversity is to map the systems of behavior regulation in terms of the functional aspects of behavioral tasks. Systems of behavior regulation developed in evolution in tune with aspects of human activities that were universal across tasks (i.e., their duration, changeability, social vs. physical nature, level of abstraction, etc). Analyzing systems from the perspective of a small set of such universal functional features of activities opens the possibility for a more compact and formal presentation of human diversity, including symptoms of mental disorders. This functional perspective was implemented in the neurochemical "Functional Ensemble of Temperament (FET)" model that was developed utilizing the Structure of Temperament Questionnaire (Rusalov and Trofimova, 2007; Trofimova, 2010a,b; Trofimova, 2015b; Trofimova and Robbins, 2016).

Temperament, i.e., biologically based individual differences in healthy people, and mental illnesses are considered as varying degrees along the same continuum of neurotransmitter imbalance in neurophysiological systems of behavioral regulation (Clark et al., 1994; Heath et al., 1994; Mehrabian, 1995; Ball et al., 1999; Weinstock and Whisman, 2006; Brown, 2007; Rusalov and Trofimova, 2007; Weiss et al., 2009; Karam et al., 2010; Trofimova, 2015b). Many temperament traits (such as impulsivity, sensation seeking, neuroticism, endurance, plasticity, sociability, extraversion) have been linked to brain neurotransmitters and hormonal systems, i.e., the very same systems implicated in mental disorders (Gray, 1982; Cloninger, 1986; Heath et al., 1994; Kagan et al., 1994; Depue and MorroneStrupinsky, 2005; Trofimova and Sulis, 2010; Zentner and Shiner, 2012; Trofimova, 2015b; Trofimova and Robbins, 2016; Trofimova and Sulis, submitted).

A temperament model, carefully structured to reflect weak imbalances within neurotransmitter systems of behavior regulation (emerging as temperament), should exhibit distinct profiles in the presence of illness consistent with DSM-V symptoms of such illness. The majority of studies investigating the coupling of temperament with mental illness describe associations of emotionality-related traits of temperament but have poor differentiation between non-emotionality aspects of behavior. Thus, anxiety disorders were associated with higher scores on Neuroticism/Negative Affect scales within Watson's Positive/Negative Affects model (Clark et al., 1994; Weinstock and Whisman, 2006; Brown, 2007; Sellbom et al., 2008), Mehrabian's model (Mehrabian, 1995), Cloninger's model (TCI) (Heath et al., 1994), Trofimova's FET model (Trofimova and Sulis, 2010; Trofimova and Christiansen, 2016; Trofimova and Sulis, submitted), Akiskal's model (Karam et al., 2010) and the Big Five model (Ball et al., 1999; Weiss et al., 2009; Kotov et al., 2010; Watson and Naragon-Gainey, 2014). Neuroticism, however, appeared to be high in many types of mental illness and therefore did not differentiate between mental disorders.
For example, in addition to the association between high Neuroticism and anxiety disorders, Neuroticism/Negative Affect was also reported to have significant positive correlation with depression (Mineka et al., 1998; Ball et al., 1999; Weinstock and Whisman, 2006; Brown, 2007; Sellbom et al., 2008; Karam et al., 2010; Kotov et al., 2010; Watson and Naragon-Gainey, 2014; Trofimova and Christiansen, 2016). Patients with histrionic personality disorder and major depression also scored higher on the Harm Avoidance scale (similar to Neuroticism, it describes an anxious disposition to novelty and uncertainty) in studies using Cloninger's TCI test (Cloninger, 1986; Kusunoki et al., 2001; Farmer and Seeley, 2009). This global coupling of the trait of Neuroticism with mental disorder shows that the scales measuring Neuroticism/Negative Affects in various temperament models are not sufficient to differentiate between different aspects of healthy behavior and between types of diagnoses in mental illness.

In contrast, the FET model considers 12 temperament traits in a $3 \times 4$ matrix: nine activity-related traits (energetic, dynamic, and orientational) each assessed in three domains (physical, social, and intellectual) together with three systems related to emotionality (Neuroticism, Impulsivity, and Self-confidence). For example, energetic systems emerge in temperament as traits of Endurance, i.e., the ability of an individual to sustain prolonged and/or intense activities. The FET model considers three types of Endurance - Physical, Social, and Intellectual (mental, i.e., attention). Differentiation between physical and social aspects of behavior in psychological assessment and in models of human diversity was first proposed by Nebylitzyn and Rusalov within the longest experimental tradition in studying properties of nervous systems (Strelau, 1998; Rusalov and Trofimova, 2007). Using human subjects, they performed a wide range of psychophysical experiments such as evoked potentials, absolute thresholds in visual, auditory, and tactile modalities, strengths of excitation and mobility in auditory and visual modalities. This research resulted in the first activity-specific model of temperament linking temperament traits to the functional components (aspects) of activities and also separating physical and social traits of temperament (Rusalov, 1979, 1989; Rusalov and Trofimova, 2007).

Rusalov's model was recently revised (Rusalov and Trofimova, 2007; Trofimova, 2010a,b; Trofimova and Sulis, 2011) and complemented by an analysis of the functionality of neurochemical systems in the form of the FET. The nine FET non-emotionality traits are posited to be regulated by monoamine (MA) and neuropeptide systems, whereas the three emotionality-related traits emerge from a dysregulation of opioid receptors systems that have direct control over MA systems (see Trofimova, 2015b; Trofimova and Robbins, 2016 for details). The FET model suggests that there is no one-to-one correspondence between the neurotransmitter systems underlying temperament traits (or mental disorders) but instead specific ensemble associations between these systems emerge as temperament traits.

For example, FET views the Neuroticism trait as a slight disregulation within kappa- (KOPr), mu-opioid receptors (MOPrs) systems and their regulation of MA release, which in 
more extreme dysregulation can lead to GAD. This suggestion is based on the findings that kappa-opioid receptors (KOPr) are important players in chronic anxiety, behavioral mobilization and arousal, and in animals with KOPr deficiency the expression of stress-related hormones is significantly reduced (degli Uberti et al., 1995; Yamauchi et al., 1997; Carlezon et al., 2009; Schwarzer, 2009; Bruchas et al., 2010; Bodnar, 2011). A dysregulation of MOPr receptors (normally suppressing KOPr activation but failing to do so in chronic anxiety) brings not only behavioral arousal but also a component of dysphoria, resulting from imbalances in the supply/demand of endorphins binding these receptors. Since both KOPr and MOPr regulate release of MAs, this can explain the links between MAs and anxiety disorders. There is a solid body of evidence that KOPr activation induces noradrenalin release and the HPA axis arousal (Takahashi et al., 1990; Simonin et al., 1995; Filliol et al., 2000; Tanaka et al., 2000; Phelps et al., 2006; Reyes et al., 2007, 2009; Schwarzer, 2009; Wittmann et al., 2009). Both KOPr and MOPr systems appear to regulate not only noradrenalin release but also GABA release (also linked to anxiety disorders) and reciprocal glutamate release (Bodnar, 2011) in a selective manner (Tanaka et al., 2000; Nagi and Piñeyro, 2011).

There are neurochemical systems that are specifically linked to social aspects of behavior, such as prolactin (Panksepp, 1998) and oxytocin (Bielsky and Young, 2004; Depue and MorroneStrupinsky, 2005; Taylor et al., 2006; Donaldson and Young, 2008; Barraza and Zak, 2009). Both serotonin and MOPrs systems regulate oxytocin and vasopressin, and are also linked to social behavior (Keverne and Curley, 2004; Barr et al., 2008; Way et al., 2009). The interaction between MOPr, serotonin, noradrenalin and oxytocin systems suggests that GAD might be marked by a decrease in social (affiliative) aspects of behavior, when MOPr and MA systems are out of balance.

For many years it was reported that temperament traits were stable or static over time, unchanging after age 30 . However, many age-related changes are linked to hormonal, endocrine and neuropeptidic changes, and since temperament traits are also based on neurochemical systems of behavior regulation, it is reasonable to suggest that there might be age differences in correlations between temperament traits and the scales measuring mental illness, especially physical, and social. Similarly, sex differences, also linked to hormonal and endocrine systems, might emerge as differences in temperament profiles and susceptibility to mental illness. For example, it is well-documented that men have on average greater upper body strength, higher rates of risk- and sensation seeking and openness to experience (Costa et al., 2001; Zuckerman, 2007; Trofimova, 2015a). Women, on the other hand, have higher rates of sociability in comparison to men (Trofimova, 2013, 2015a).

\section{Generalized Anxiety Disorder: An Example}

Here we present an example of the benefits obtained from differentiating between physical, social-verbal, and mental aspects of behavioras proposed by the FET model. The hypothesis of this study was in line with the main DSM-V descriptor of GAD related to the presence of worrying: this symptom was expected to emerge in higher scores on the Neuroticism scale in GAD patients, in comparison to controls. In addition, the FET hypothesis predicted that GAD patients might have a decrease in Social-verbal Endurance (sociability). Assessment data from the intake records of $262(\mathrm{M} / \mathrm{F}=111 / 151)$ Canadians, patients and associates of a private psychiatric and psychological practice (Psychological Services 4018 having four distant locations in Southern Ontario, Canada) were analyzed. The practice has its own Late Life Memory Clinic (Haldimand War Memorial Hospital, Dunnville, ON, Canada) that provides screening for dementia in clients and patients over 60. The sample was divided into those who were diagnosed with GAD $(N=116$, $\mathrm{M} / \mathrm{F}=47 / 69)$ and those who did not have mental illness $(N=146, \mathrm{M} / \mathrm{F}=64 / 82)$. GAD patients were divided into three age groups: Age1: 17-24 years-old (Mean age 19.42, $S D=2.13$ ), $\mathrm{M} / \mathrm{F}=21 / 31, N=52 ;$ Age2: $25-45$ years-old $(M=35.28$, $S D=6.13), \mathrm{M} / \mathrm{F}=14 / 20, N=34$, Age3: $46-65$ years-old $(M=53.86, S D=5.45), M / F=12 / 18, N=30$. Subsample of healthy subjects was also divided into age groups of the same range: Age1: $N=70, \mathrm{M} / \mathrm{F}=28 / 42$; Age2: $N=46, \mathrm{M} / \mathrm{F}=23 / 23$; Age3: $N=30, \mathrm{M} / \mathrm{F}=13 / 17$. The prevalence of females in the sample reflected the female prevalence in patients with GAD in the general population. The subsample of healthy people was structured to reflect the structure of the GAD subsample to enable a balanced statistical analysis. The "Anxiety" group consisted of patients diagnosed with generalized anxiety disorder (GAD) (moderate to severe) on the basis of the structured DSM-IV clinical interview, file review, testing and a prolonged period of subsequent treatment. Testing included the Beck Anxiety Inventory (GAD group included patients with scores of 36 or higher), State Trait Anxiety Inventory (scores of 61 or higher), Post-Traumatic Stress diagnostic scale and Symptom CheckList90 (scores of 31 or higher on the Anxiety scale).

\section{Procedure and Measures}

All healthy participants of this study, as well as non-dementing clients and patients gave consent allowing the use of their intake forms for research purposes. During either intake testing (for patients and clients) or research (for healthy participants) each person completed the Compact Structure of Temperament Questionnaire (STQ-77) (Rusalov and Trofimova, 2007; Trofimova, 2010a,b; Trofimova and Sulis, 2011) ${ }^{1}$. The STQ77 consists of 77 statements, assigned to 12 temperament scales (six items each) and a validity scale (five items, addressing social desirability bias), which are listed below. Subjects responded according to a 4-point Likert scale format: (1) "strongly disagree," (2) “disagree," (3) “agree," (4) "strongly agree."

The temperament scales are organized in groups as following:

1-3: Endurance scales - Motor (ERM, alpha Cronbach for this data $=0.81$ ), Social (ERS, $\alpha=0.78$ ) and Intellectual Endurance (ERI, $\alpha=0.73$ ) (the ability of an individual to sustain prolonged physical, social or mental activity, respectively).

${ }^{1}$ The complete validation history can be found in Rusalov and Trofimova (2007) and Trofimova (2010a,b). 
4-5: Dynamic scales - Motor (TMM, $\alpha=0.80$ ) and Social Tempo (TMS, $\alpha=0.74$ ) (preferred speed of physical activity, or speed of speech and reading and of other verbal activities, respectively) and Plasticity (PL, $\alpha=0.72$ ), (the ability to adapt quickly to changing situations, to change plans, to shift between tasks).

6-9: Orientation scales - Sensation Seeking (SS, $\alpha=0.73$ ), (the degree of orientation of a person to basic physical sensations and pleasures; tendency for sensationseeking and risk-taking behavior); Empathy (EMP, $\alpha=0.74$ ), (orientation to other people's emotional states), Sensitivity to Probabilities (PRO, $\alpha=0.72$ ), (orientation to probabilistic expectations, causes, and consequences of events, the efficient extraction and processing of new knowledge).

10-12: Emotionality scales - Self-confidence (SLF, $\alpha=0.71$ ), (the tendency to be optimistic and confident in one's own performance, to ignore warnings and criticism); Impulsivity (IMP, $\alpha=0.73$ ), (speed of emotionally driven actions (emotional reactivity), poor ability to control immediate impulses for actions); Neuroticism (NEU, $\alpha=0.77$ ), (low tolerance of uncertainty and novelty, negativity bias in expectations of outcomes in own activity).

13: Validity scale - social desirability tendency in answers. Results within the range of 15-20 on the validity scale should be considered invalid as the respondents are likely to demonstrate positive impression bias in their responses.

Statistical processing included descriptive scale statistics (Means, Standard Deviations, alpha Cronbach coefficient for STQ scales). The mean scores on the STQ scales from the groups contrasted by Diagnosis (GAD vs. Controls), Age (three groups) and Sex were submitted to multi-factorial ANOVA to examine the impact these three factors. Post hoc comparisons were performed using both the Tukey and Fisher LCD tests with an alpha level of 0.05 . The partial Eta-squared values $\left(\eta^{2}\right)$ were also calculated as an additional metric of effect size for all significant ANOVA contrasts.

\section{DIFFERENTIAL CONTRIBUTION OF PHYSICAL-MOTOR AND SOCIAL-VERBAL TRAITS IN GAD, AGE AND SEX DIFFERENCES}

The comparison of GAD and control groups showed that the presence of GAD was associated with significant effects on four traits. Anxious patients reported significantly lower Social Endurance, lower Social Tempo, lower Sensitivity to Probabilities and higher Neuroticism, in comparison to the control group (Table 1; Figure 1). The finding of significantly higher Neuroticism in GAD patients, in comparison to nonanxious participants is consistent with reports using other temperament models to study mental illness, with a scale of Neuroticism as part of those models as cited above. More importantly, Social Endurance (sociability) and Social Tempo were reported as decreased in the presence of GAD but Motor Endurance or Motor Tempo were unaffected. This selectivity in the effect of GAD on the energetic and dynamical aspects of activity suggests that the DSM-V criterion of fatigue as a symptom of GAD is more nuanced, and that this is observable utilizing an activity specific model such as the FET. Low sociability can interfere with a patients' ability to sustain an effective support network and to seek out help and therefore might not be a visible aspect of GAD to the community.

The differentiation between 12 traits within the FET model also appeared to be beneficial in assessment of age differences. Three significant effects of age were found in this study: lower scores on Motor Tempo and Social Tempo were reported by subjects in the older age groups, i.e., dynamical traits but not endurance- or orientation-related related traits. Such decrease is

TABLE 1 | Means and Standard Deviations $\left(M_{S D}\right)$ on the STQ-77 scales for groups contrasted by GAD (all ages combined), ANOVA effects for Anxiety factor and $\eta^{2}$ for Anxiety, Sex, and Age factors.

\begin{tabular}{|c|c|c|c|c|c|c|}
\hline $\begin{array}{l}\text { STQ-77 } \\
\text { Scales }\end{array}$ & $\begin{array}{c}\text { Controls } N=146 \\
M_{S D}\end{array}$ & $\begin{array}{c}\text { Anxious } N=116 \\
M_{S D}\end{array}$ & $\begin{array}{l}\text { Effect of } \\
F(1,250)\end{array}$ & $\begin{array}{c}\text { Anxiety } \\
\eta^{2}\end{array}$ & $\begin{array}{c}\text { Sex } \\
\eta^{2}\end{array}$ & $\begin{array}{c}\text { Age } \\
\eta^{2}\end{array}$ \\
\hline Motor Endurance & $16.87_{3.77}$ & $16.48_{3.41}$ & 1.18 & 0.005 & $0.022 *$ & 0.018 \\
\hline Motor Tempo & $16.78_{3.32}$ & $16.27_{3.23}$ & 0.21 & 0.001 & 0.012 & $0.027^{*}$ \\
\hline Sensation Seeking & $15.50_{3.63}$ & $14.73_{3.94}$ & 1.39 & 0.005 & 0.147 & 0.150 \\
\hline Social Endurance & $17.64_{3.66}$ & 15.844 .00 & $11.92^{* * *}$ & 0.045 & $0.021 *$ & 0.002 \\
\hline Social Tempo & $16.12_{3.31}$ & $14.90_{3.49}$ & $5.90^{*}$ & 0.23 & $0.048^{* * *}$ & $0.028^{*}$ \\
\hline Empathy & $16.85_{3.49}$ & $16.89_{4.09}$ & 0.01 & 0.001 & 0.007 & 0.001 \\
\hline Intellectual Endurance & $16.48_{3.10}$ & $15.87_{3.67}$ & 0.67 & 0.002 & 0.004 & 0.021 \\
\hline Plasticity & 15.962 .95 & $15.34_{3.31}$ & 1.55 & 0.006 & 0.001 & 0.019 \\
\hline Sensitivity to Probabilities & $17.16_{3.26}$ & $16.19_{3.43}$ & $4.03^{*}$ & 0.046 & $0.046^{* * *}$ & 0.009 \\
\hline Self-Confidence & $16.12_{3.04}$ & $15.28_{3.68}$ & 2.19 & 0.009 & 0.000 & 0.005 \\
\hline Impulsivity & 14.473 .32 & 15.514 .42 & 2.88 & 0.011 & 0.012 & $0.038^{* *}$ \\
\hline Neuroticism & $15.31_{3.18}$ & $17.71_{3.72}$ & $26.52^{* * *}$ & 0.095 & 0.004 & 0.007 \\
\hline
\end{tabular}

${ }^{*} p<0.05,{ }^{* *} p<0.01,{ }^{* * *} p<0.001 ; N=292$. 

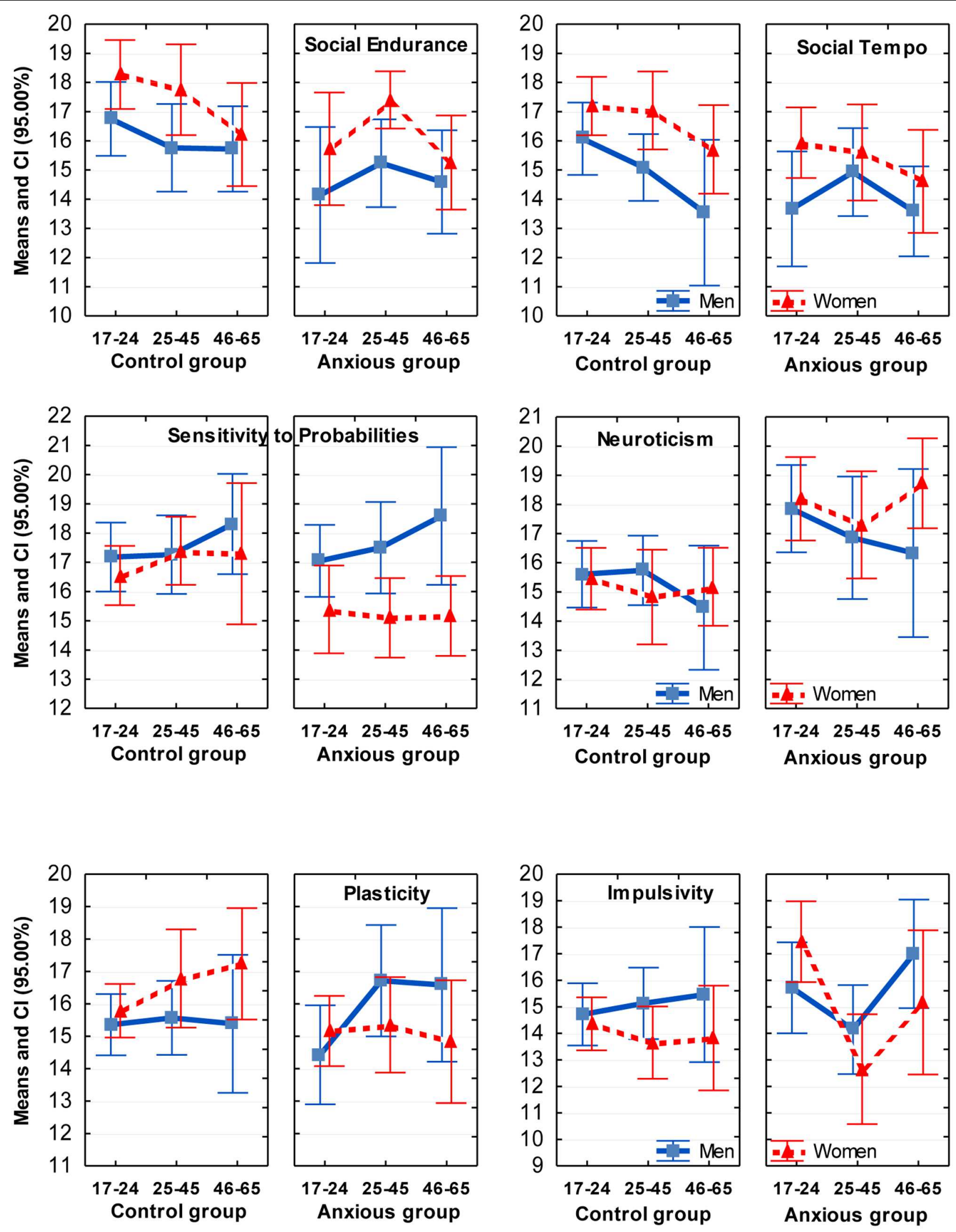

FIGURE 1 | Means and Confidence Intervals (CI) of the scores on temperament scales which showed coupling with GAD (first four graphs). Sex differences were especially significant on the scales of Social Tempo and Sensitivity to Probabilities. Interaction effects with GAD with sex were found on the scales of Plasticity and Sensitivity to Probabilities; with age - on the scale of Impulsivity. 
consistent with reports that speed of activities declines with age in both men and women (Birren and Schaie, 1990; Trofimova and Christiansen, 2016; Trofimova and Sulis, submitted). A significant interaction effect between age and GAD appeared in relation to Impulsivity $\left(F=4.00, p=0.019 ; \eta^{2}=0.031\right)$. In the presence of GAD the youngest (17-24 years-old) women reported higher Impulsivity than other groups whereas in groups aged 25-65 women appeared to have the best impulse control, even in the GAD group.

There were four significant sex differences: Motor Endurance and Sensitivity to Probabilities were reported higher by men, while Social Endurance and Social Tempo were reported higher by women, consistent with other reports using young age samples (Bishop et al., 1987; Nyborg, 1994; Collaer and Hines, 1995; Trofimova, 2013). There were three significant interactions between Sex and Anxiety factors, on the scales of Sensitivity to Probabilities $\left(F=5.30, p=0.022 ; \eta^{2}=0.021\right)$, Plasticity $\left(F=5.80, p=0.016, \eta^{2}=0.023\right)$ and Self-confidence $(F=4.55$, $\left.p=0.033, \eta^{2}=0.018\right)$. Post hoc analysis showed that anxious women reported significantly lower scores on these scales, in comparison to the anxious men and to non-anxious women. Interestingly, a rather long held cultural stereotype that portrays women as being more neurotic and histrionic than men was most definitely not supported in this study. Healthy men and women across all age groups reported similar scores in Neuroticism and Self-confidence. Sex differences emerged only in the presence of GAD. It appeared that the presence of GAD was associated with lower scores on Self-confidence, Plasticity and Sensitivity to Probabilities in women much more than in men.

\section{CONCLUSION}

The FET framework for differentiating between 3 emotionality aspects and nine functional aspects of behavior: endurance,

\section{REFERENCES}

Ball, S. A., Tennen, H., Poling, J. C., Kranzlen, H. R., and Rounsaville, B. J. (1999). Personality, temperament, and character dimensions and the DSM-IV personality disorders in substance abusers. J. Abn. Psychol. 106, 545-553. doi: 10.1037/0021-843X.106.4.545

Barr, C. S., Schwandt, M. L., Lindell, S. G., Higley, J. D., Maestripieri, D., Goldman, D., et al. (2008). Variation at the mu-opioid receptor gene (OPRM1) influences attachment behavior in infant primates. Proc. Nat. Acad. Sci. U.S.A. 105, 5277-5281. doi: 10.1073/pnas.0710225105

Barraza, J. A., and Zak, P. J. (2009). Empathy toward strangers triggers oxytocin release and subsequent generosity. Ann. N.Y. Acad. Sci. 1167, 182-189. doi: 10.1111/j.1749-6632.2009.04504.x

Bielsky, I. F., and Young, L. J. (2004). Oxytocin, vasopressin, and social recognition in mammals. Peptides 25, 1565-1574. doi: 10.1016/j.peptides.2004.05.019

Birren, J. E., and Schaie, K. W. (eds). (1990). Handbook of the Psychology of Aging, 3rd Edn. New York: Academic Press.

Bishop, P., Cureton, K., and Collins, M. (1987). Sex difference in muscular strength in equally-trained men and women. Ergonomics 30, 675-687. doi: $10.1080 / 00140138708969760$

Bodnar, R. J. (2011). Endogenous opiates and behaviour. Peptides 32, 2522-2552. doi: 10.1016/j.peptides.2011.09.020

Brown, T. A. (2007). Temporal course and structural relationships among dimensions of temperament and DSM-IV anxiety and mood disorder speed of integration of an action and orientation, considered separately in physical, social, and mental domains, appears to be quite useful for studying individual differences. This framework offers dimensions for mapping symptoms of mental illness, such as GAD. Such dimensionality can bring more insights about symptoms of mental illness, sex and age differences. For example, our study found that the current GAD criterion of fatigue would benefit from being related more to social-verbal and less to physical aspects of endurance. Future directions include studies investigating the benefits of differentiating between 12 components of the FET model in samples of patients with various mental illnesses. Examples of potential applications of this perspective relate to: (1) a new classification of psychiatric disorders based on functional aspects of arousal described within the FET model, as a contribution to the NIH initiative on Research Domain Criteria (Insel, 2014; Trofimova and Sulis, submitted); (2) new insights for research in psychopharmacology, and (3) mapping temperamental profiles associated with dispositions to specific psychiatric disorders.

\section{AUTHOR CONTRIBUTIONS}

WS participated in the development of the study, in data collection, and analysis, in writing and editing the manuscript and in giving final approval. IT led in the development of the study, in data collection and analysis, in writing and editing the manuscript and in giving final approval.

\section{FUNDING}

This study was self funded.

constructs. J. Abn. Psychol. 116, 313-328. doi: 10.1037/0021-843X.116. 2.313

Bruchas, M. R., Land, B. B., and Chavkas, C. (2010). The dynorphin/kappa opioid system as a modulator of stress-induced and pro-addictive behavior. Brain Res. 1314, 44-55. doi: 10.1016/j.brainres.2009.08.062

Carlezon, W. A., Béguin, C., Knoll, A. T., and Cohen, B. M. (2009). Kappaopioid ligands in the study and treatment of mood disorders. Pharm. Ther. 123, 334-343. doi: 10.1016/j.pharmthera.2009.05.008

Clark, L. A., Watson, D., and Mineka, S. (1994). Temperament, personality, and the mood and anxiety disorders. J. Abn. Psychol. 103, 103-116. doi: 10.1037/0021843X.103.1.103

Cloninger, C. R. (1986). A unified biosocial theory of personality and its role in the development of anxiety states. J. Psychol. Dev. 4, 167-226.

Collaer, M., and Hines, M. (1995). Human behavioural sex differences: a role for gonadal hormones during early development? Psychol. Bull. 118, 55-107. doi: 10.1037/0033-2909.118.1.55

Costa, P. T., Terracciano, A., and McCrae, R. R. (2001). Gender differences in personality traits across cultures: robust and surprising findings. J. Pers. Soc. Psychol. 81, 322-331. doi: 10.1037/0022-3514.81.2.322

degli Uberti, E. C., Petraglia, F., Bondanelli, M., Guo, A. L., Valentini, A., Salvadori, S., et al. (1995). Involvement of mu-opioid receptors in the modulation of pituitary-adrenal axis in normal and stressed rats. J. Endocr. Invest. 18, 1-7. doi: 10.1007/BF033 49688 
Depue, R. A., and Morrone-Strupinsky, J. V. (2005). A neurobehavioural model of affiliate bonding: implications for conceptualizing a human trait of affiliation. J. Behav. Brain Sci. 28, 313-350.

Donaldson, Z. R., and Young, L. J. (2008). Oxytocin, vasopressin, and the neurogenetics of sociality. Science 322, 900-904. doi: 10.1126/science. 1158668

Farmer, R. F., and Seeley, J. R. (2009). Temperament and character predictors of depressed mood over a 4-year interval. Depress Anxiety 26, 371-381. doi: 10.1002/da.20459

Filliol, D., Ghozland, S., Chluba, J., Martin, M., Matthes, H. W., Simonin, F., et al. (2000). Mice deficient for delta- and mu-opioid receptors exhibit opposing alterations of emotional responses. Nat. Genet. 25, 195-200. doi: 10.1038/ 76061

Gray, J. A. (1982). The Neuropsychology of Anxiety: an Enquiry into the Functions of the Septo-Hippocampal System. Oxford: Oxford University Press.

Heath, A. C., Cloninger, C., and Martin, N. G. (1994). Testing a model for the genetic structure of personality: a comparison of the personality systems of Cloninger and Eysenck. J. Person. Soc. Psychol. 66, 762-775. doi: 10.1037/00223514.66.4.762

Insel, T. R. (2014). The NIMH research domain criteria (RDoC) project: precision medicine for psychiatry. Am. J. Psychol. 171, 395-397. doi: 10.1176/appi.ajp.2014.14020138

Kagan, J., Snidman, N., Arcus, D., and Reznick, J. S. (1994). Galen's Prophecy: Temperament in Human Nature. New York: Basic Books.

Karam, E. G., Salamoun, M. M., Yeretzian, J. S., Neimneh, Z. N., Karam, A. N., Fayad, J., et al. (2010). The role of anxious and hyperthymic temperaments in mental disorders: a national epidemiologic study. World Psychol. 9, 103-110. doi: 10.1002/j.2051-5545.2010.tb00287.x

Keverne, E. B., and Curley, J. P. (2004). Vasopressin, oxytocin, and social behaviour. Curr. Opin. Neurobiol. 14, 777-783. doi: 10.1016/j.conb.2004.10.006

Kotov, R., Gamez, W., and Schmidt, F. D. (2010). Linking "big” personality traits to anxiety, depressive and substance use disorders: a meta-analysis. Psychol. Bull. 136, 768-821. doi: 10.1037/a0020327

Kusunoki, K., Sato, T., Taga, C., Yoshida, Y., Komori, K., Narita, T., et al. (2001). Low novelty-seeking differentiates obsessive-compulsive disorder from major depression. Acta Psychiatr. Scand. 101, 403-405. doi: 10.1034/j.16000447.2000.101005403.x

Mehrabian, A. (1995). Distinguishing depression and trait anxiety in terms of basic dimensions of temperament. Imag. Cogn. Pers. 15, 133-143. doi: 10.2190/JB3JLL1E-GYGY-D0RJ

Mineka, S., Watson, D., and Clark, L. A. (1998). Comorbidity of anxiety and unipolar mood disorders. Annu. Rev. Psychol. 49, 377-412. doi: 10.1146/annurev.psych.49.1.377

Nagi, K., and Piñeyro, G. (2011). Regulation of opioid receptor signalling: implications for the development of analgesic tolerance. Mol. Brain 4:25. doi: 10.1186/1756-6606-4-25

Nyborg, H. (1994). Hormones, Sex and Society. Westport, CT: Praeger.

Panksepp, J. (1998). Affective Neuroscience: The Foundations of Human and Animal Emotions. Oxford: Oxford University Press.

Phelps, E. A., Ling, S., and Carrasco, M. (2006). Emotion facilitates perception and potentiates the perceptual benefits of attention. Psychol. Sci. 17, 292-299. doi: 10.1111/j.1467-9280.2006.01701.x

Reyes, B. A., Chavkin, C., and van Bockstaele, E. J. (2009). Subcellular targeting of kappa-opioid receptors in the rat nucleus locus coeruleus. J. Comp. Neurol. 512, 419-431. doi: 10.1002/cne.21880

Reyes, B. A., Johnson, A. D., Glaser, J. D., Commons, K. G., and Van Bockstaele, E. J. (2007). Dynorphin-containing axons directly innervate noradrenergic neurons in the rat nucleus locus coeruleus. Neuroscience 145, 1077-1086. doi: 10.1016/j.neuroscience.2006.12.056

Rusalov, V. M. (1979). Biologicheskiye Osnovi Individual'no-Psichologicheskih Razlichiy. (Biological Basis of Individual Psychological Differences). Moscow: Nauka Publications.

Rusalov, V. M. (1989). Motor and communicative aspects of human temperament: a new questionnaire of the structure of temperament. Pers. Individ. Differ. 10, 817-827. doi: 10.1016/0191-8869(89)90017-2

Rusalov, V. M., and Trofimova, I. N. (2007). Structure of Temperament and its Measurement. Toronto: Psychological Services Press.
Schwarzer, C. (2009). 30 Years of Dynorphins - New insights on their functions in neuropsychiatric diseases. Pharm. Ther. 123, 353-370. doi: 10.1016/j.pharmthera.2009.05.006

Sellbom, M., Ben-Porath, Y. S., and Bagby, R. M. (2008). On the hierarchical structure of mood and anxiety disorders: confirmatory evidence and elaboration of a model of temperament markers. J. Abnorm. Psychol. 117, 576-590. doi: 10.1037/a0012536

Simonin, F., Gaveriaux-Ruff, C., Befort, K., Matthes, H., Lannes, B., Micheletti, G., et al. (1995). kappa-Opioid receptor in humans: cDNA and genomic cloning, chromosomal assignment, functional expression, pharmacology, and expression pattern in the central nervous system. Proc. Nat. Acad. Sci. U.S.A. 92, 7006-7010. doi: 10.1073/pnas.92.15.7006

Strelau, J. (1998). Temperament: A Psychological Perspective. New York: Plenum.

Takahashi, M., Senda, T., Tokuyama, S., and Kaneto, H. (1990). Further evidence for the implication of a kappa-opioid receptor mechanism in the production of psychological stress-induced analgesia. Japan. J. Pharm. 53, 487-494. doi: 10.1254/jjp.53.487

Tanaka, M., Yoshida, M., Emoto, H., and Ishii, H. (2000). Noradrenaline systems in the hypothalamus, amygdala and locus coeruleus are involved in the provocation of anxiety: basic studies. Euro. J. Pharm. 405, 397-406. doi: 10.1016/S0014-2999(00)00569-0

Taylor, S. E., Gonzaga, G. C., Klein, L. C., Hu, P., Greendale, G. A., and Seeman, T. E. (2006). Relation of oxytocin to psychological stress responses and hypothalamic-pituitary-adrenocortical axis activity in older women. Psychosom. Med. 68, 238-245. doi: 10.1097/01.psy.0000203242.95990.74

Trofimova, I. (2010a). An investigation into differences between the structure of temperament and the structure of personality. Am. J. Psychol. 123, 467-480. doi: 10.5406/amerjpsyc.123.4.0467

Trofimova, I. (2010b). Questioning the "general arousal" models. Open. Behav. Sci. Psychol. 4, 1-8. doi: 10.2174/1874230001004010001

Trofimova, I. (2013). A study of the dynamics of sex differences in adulthood. Int. J. Psychol. 47, 1-7. doi: 10.1080/00207594.2012.756981

Trofimova, I. (2014). Observer bias: an interaction of temperament traits with biases in the semantic perception of lexical material. PLOS ONE 9:e85677. doi: 10.1371/journal.pone.0085677

Trofimova, I. (2015a). Do psychological sex differences reflect evolutionary bisexual partitioning? Am. J. Psychol. 128, 4.

Trofimova, I. (2015b). "The interlocking between functional aspects of activities and a neurochemical model of adult temperament," in Temperaments: Individual Differences, Social and Environmental Influences and Impact on Quality of Life, ed. M. C. Arnold (New York, NY: Nova Science Publishers, Inc.).

Trofimova, I., and Christiansen, J. (2016). Coupling of temperament traits with mental illness in four age groups. Psychol. Rep. 118, 511-532. doi: $10.1177 / 0033294116639430$

Trofimova, I., and Robbins, T. W. (2016). Temperament and arousal systems: a new synthesis of differential psychology and functional neurochemistry. Neurosci. Biobehav. Rev. (in press). doi: 10.1016/j.neubiorev.2016.03.008

Trofimova, I., and Sulis, W. (2010). The lability of behaviour as a marker of comorbid depression and anxiety. Adv. Biosci. Biotechnol. 1, 190-199. doi: 10.4236/abb.2010.13027

Trofimova, I., and Sulis, W. (2011). Is temperament activity-specific? Validation of the structure of temperament questionnaire-compact STQ-77. Int. J. Psychol. Psychol. Ther. 11, 389-400.

Watson, D., and Naragon-Gainey, K. (2014). Personality, emotions, and the emotional disorders. Clin. Psychol. Sci. 2, 422-442. doi: 10.1177/216770 2614536162

Way, B. M., Taylor, S. E., and Eisenberger, N. I. (2009). Variation in the muopioid receptor gene (OPRM1) is associated with dispositional and neural sensitivity to social rejection. Proc. Nat. Acad. Sci. U.S.A. 106, 15079-15084. doi: 10.1073/pnas.0812612106

Weinstock, L. M., and Whisman, M. A. (2006). Neuroticism as a common feature of the depressive and anxiety disorders: a test of the revised integrative hierarchical model in a national sample. J. Abn. Psychol. 115, 68-74. doi: 10.1037/0021-843X.115.1.68

Weiss, A., Sutin, A. R., Duberstein, P. R., Friedman, B., Bagby, R. M., and Costa, P. T. (2009). The personality domains and styles of the fivefactor model are related to incident depression in Medicare recipients aged 
65 to 100. Am. J. Ger. Psych. 1, 591-601. doi: 10.1097/JGP.0b013e31819 d859d

Wittmann, W., Schunk, E., Rosskothen, I., Gaburro, S., Singewald, N., Herzog, H., et al. (2009). Prodynorphin-derived peptides are critical modulators of anxiety and regulate neurochemistry and corticosterone. Neuropsychopharmacology 34 , 775-785. doi: 10.1038/npp.2008.142

Yamauchi, N., Shibasaki, T., Wakabayashi, I., and Demura, H. (1997). Brain beta-endorphin and other opioids are involved in restraint stress-induced stimulation of the hypothalamic-pituitary-adrenal axis, the sympathetic nervous system, and the adrenal medulla in the rat. Brain Res. 777, $140-146$.

Zentner, M., and Shiner, R. (Eds). (2012). Handbook of Temperament. New York, NY: Guilford Press, 750.
Zuckerman, M. (2007). Sensation Seeking and Risky Behavior. Washington, DC: APA Press.

Conflict of Interest Statement: The authors declare that the research was conducted in the absence of any commercial or financial relationships that could be construed as a potential conflict of interest.

Copyright (@) 2016 Trofimova and Sulis. This is an open-access article distributed under the terms of the Creative Commons Attribution License (CC BY). The use, distribution or reproduction in other forums is permitted, provided the original author(s) or licensor are credited and that the original publication in this journal is cited, in accordance with accepted academic practice. No use, distribution or reproduction is permitted which does not comply with these terms. 